\title{
Developmental Differences in Affective Representation Between Prefrontal and Subcortical Structures
}

\author{
William J. Mitchell a, william.j.mitchell@temple.edu * \\ Lindsey J. Tepfer ${ }^{\text {b }}$, lindsey.j.tepfer.gr@dartmouth.edu \\ Nicole M. Henninger c, henninger.nicole@temple.edu \\ Vishnu P. Murty a, vishnu.murty@temple.edu \\ Chelsea Helion a, chelsea.helion@temple.edu \\ Susan B. Perlman ${ }^{d}$, perlmansusan@wustl.edu
}

\section{a) Department of Psychology}

Weiss Hall, Temple University, $1701 \mathrm{~N} 13^{\text {th }}$ St. Philadelphia, PA, USA 19122

b) Department of Psychological and Brain Sciences

Moore Hall, Dartmouth College, 3 Maynard St, Hanover, NH, USA 03755

c) Klein College of Media and Communication

Annenberg Hall, Temple University, 2020 N. 13th St. Philadelphia, PA, USA 19122

d) Department of Psychiatry

Washington University of St. Louis, 660 S Euclid Ave, St. Louis, MO, USA 63110

${ }^{*}$ Corresponding author.

E-mail address: william.j.mitchell@temple.edu

Address: 717 Weiss Hall, Temple University, $1701 \mathrm{~N} 13^{\text {th }}$ St. Philadelphia, PA 19122 


\begin{abstract}
Developmental studies have identified differences in prefrontal and subcortical affective structures between children and adults, which correspond with observed cognitive and behavioral maturations from relatively simplistic emotional experiences and expressions to more nuanced, complex ones. However, developmental neurocognitive affective changes have not yet been well explored. It stands to reason that adults and children may demonstrate observable differences in the representation of affect within key neurological structures implicated in affective cognition. Forty-five participants (25 children; 20 adults) passively viewed positive, negative, and neutral clips from popular films while undergoing functional magnetic resonance imaging. Using representational similarity analysis to measure variability in neural pattern similarity, we found developmental differences between children and adults in the amygdala, nucleus accumbens, and ventromedial prefrontal cortex, such that children generated contrasting patterns between subcortical structures and the ventromedial prefrontal cortex; a phenomenon not replicated among their older counterparts. Furthermore, children generated valence-specific differences in representational patterns across regions while adults failed to demonstrate similar valence-specific responses. These results may suggest that affective representations grow increasingly dissimilar over development as individuals mature from visceral affective responses to more evaluative analyses. Further research is required to determine how these differences correspond with affective expression and behavior.
\end{abstract}




\section{Keywords (5):}

Affect ;

Representational Similarity Analysis ;

Development ;

Ventromedial Prefrontal Cortex ;

Subcortical Region 


\subsection{Introduction}

A transition away from overt emotional reactivity is commonly observed over the course of early development (Karim \& Perlman, 2017), and such age-related adaptations may be critical for successful functioning in the complex array of social and affective contexts that comprise adulthood (Camacho et al., 2019). Some have argued that the emotional granularity of adults and children is comparable, pointing to research that has found children and adults report similar levels of emotional reactivity, but differ in how they manage their responses when viewing affectively valenced stimuli (Silvers et al., 2012). While individuals undoubtedly experience nuanced and powerful emotions throughout their lifespan, expressions of affectively-relevant information change over development.

Children as young as 2 years old use language to express emotions (Wellman et al., 1995). However, the complexity of these expressions of emotion, as well as recognition of others' emotions (Fabes et al., 1991), increases with age through early development. This development seems to be a function of social context, as family (Dunn, Brown, \& Beardsall, 1991), peers (Fabes et al., 1991), and language development (de Rosnay \& Harris, 2002; Pons et al., 2003; Nook et al., 2017; Hoemann, Xu, \& Barrett, 2019) have an influence, with greater experiential variation resulting in greater individual differences. Researchers have postulated that these mediums function to improve mental representations of affective information (Pons et al., 2003). Differentiation models of emotional development, such as those championed by Widen \& Russell $(2003,2010)$ suggest that children begin with relatively simple, binarized categories, falling along lines of valence (i.e., Positive/Negative; Pons, Harris, de Rosnay, 2004; Widen, 2013), but 
which progressively grow into more complex and multidimensional representations by adulthood (Russell, 1980, 2003; Widen \& Russell, 2008; Nook et al. 2017). Although by adulthood, affective valence alone can be insufficient in explaining the physiological, expressive, and experiential components of categorically congruent emotions (See Barrett 2006, 2017), valence still demonstrates predictive utility in behavior. For example, social norm violations of negative affect-related emotions elicit more punishment than those of positive affect violations (Krumhuber \& Manstead, 2009; Ansfield, 2007; Szezurek, Monin, and Gross, 2012). However, signatures of differentiation in affective representations to date have primarily been documented via cognitive and behavioral studies, and the utility of neural studies for this topic is still being established.

Previous studies have identified neural regions that undergo structural and functional changes in temporal parallel with these cognitive and behavioral developments, including the ventromedial prefrontal cortex (vmPFC) (Gee et al., 2013; Jalbrzikowski et al., 2017), amygdala (AMY) (Davis \& Whalen, 2000; Gabard-Durnam et al., 2014; Perlman \& Pelphrey, 2011), and nucleus accumbens (NAcc) (Levita et al., 2009). In adults, the amygdala and ventral striatum (VS), in which the NAcc is situated, may process the perception of valence and exert neuromodulatory influences on prefrontal circuitry (Davis \& Whalen, 2000; Levita et al., 2009). The vmPFC demonstrates a distinct pattern of outputs back to the amygdala and NAcc, which may function as an affect and attention network (Bhanji et al., 2019). However, the quality of the relationship between these structures may be different for young children and adults, as mPFC-amygdala connectivity alters from positive to negative around age 10, with the valenced association in region activation strengthening across normative development (Gee et al., 2013). 
Furthermore, amygdala-to-vmPFC projections emerge prior to vmPFC-to-amygdala projections in rodents (Bouwmeester et al., 2002a; 2002b), which may offer a mechanism by which to explain behavior studies finding that adults demonstrate greater emotional stability than children (Larson et al., 1980; Noftle \& Fleeson, 2010; Silvers et al., 2017), as younger individuals may be at a deficit to modulate affective experiences via prefrontalsubcortical feedback loops. While the vmPFC has been broadly linked to affective evaluations and emotion (Hiser \& Koenigs, 2018; Greene, 2007; Moll \& de OliveiraSouza, 2007; Winecoff et al., 2013; Yang et al., 2018), it has been specifically tied to neural signatures of emotion classification in adults (Saarimaki et al., 2016), and changes in classification may actively shape neural representations within the mPFC, as well as the amygdala and ventral anterior insula (Satpute et al., 2016). This may suggest that prefrontal development is a crucial component in emotion differentiation development as well.

Although much is known about the functional and structural connections among these structures, it's not well understood how information is neurally represented across varying spatial scales (Haxby et al., 2014). Most of the investigations exploring neural mechanisms behind developmental changes in affectivity employ univariate methods (Camacho et al., 2019), which obscure the more granular voxel-level differences that might be present among adults and children (Popal et al., 2019). For instance, if a univariate examination finds no difference between group responses when viewing affectively valenced stimuli, it is unclear whether there exist granular and informative differences, as any potential variations are subsumed when neural responses are averaged together. Techniques such as representational similarity analysis (RSA) 
(Kriegeskorte et al., 2008) allow us to relate condition pairs using a metric that measures dissimilarity, or similarity, depending upon the framing, between groups of correlative pairs and corresponding patterns of neural activity responding to each type of stimuli (Dimsdale-Zucker \& Ranganath, 2018). Thus, the aim of this research is to further our understanding of developmental differences in affective representation using more modern methodology.

\subsection{Study Goals and Hypotheses}

We applied an RSA approach to neuroimaging data collected from a sample of adults and children who viewed videos of both positive and negative affective social scenes from popular children's movies, as well as neutrally valenced control stimuli, in order to determine whether developmental differences exist in affective representations. This was a secondary analysis of data originally collected by Karim \& Perlman (2017), which solely investigated univariate activation and did not explore affective representations in the amygdala, NAcc, or vmPFC.

In line with developmental research suggesting the development of greater affective expressive and comprehension complexity with age, we hypothesized that children would generate greater pattern similarity relative to their older counterparts in response to valenced stimuli. Furthermore, due to the late functional development of the vmPFC, as well as the late development of projections from the mPFC region to subcortical structures, we expected that the difference in representational pattern similarity between children and adult subcortical ROIs (amygdala \& NAcc) would be less than the difference between adults and children in the vmPFC. Understanding how 
children process representations of affectively valenced stimuli contributes not only to theories of neural processing but also provides practical knowledge of the developmental growth of higher-order thinking.

We expected that negatively valenced stimuli would generate greater representational similarity than positive valenced stimuli in both adults and children, due to evidence supporting the existence of negativity biases demonstrating reasonable consistency across individuals (Baumeister, Bratslavsky, Finkenauer, \& Vohs, 2001). We also hypothesized a relative lack of differentiation combined with the increased survival salience that negativity may signal (See O'toole et al., 2020; Pratto \& John, 1991) may result in this effect being more pronounced in children relative to adults.

\subsection{Materials \& Methods}

\subsection{Participants}

Fifty-seven English-speaking participants (36 children; 21 adults) with no history of psychiatric disorder were recruited at the University of Pittsburgh. All adult participants consented to study participation. All children assented to study participation and consent was provided by a parent. Twelve participants ( 11 children; 1 adult) were removed from analyses due to excessive head motion, resulting in an effective sample of 25 children (14 female, aged $4-10, M=7.4, S D=1.85$ ) and 20 adults (9 female, aged $20-44, M=$ 26.7,

$S D=$

\subsection{Task}


The task is explained in detail in Karim \& Perlman (2017), but pertinent details will be highlighted here as well. Participants watched twenty-four clips from films while undergoing functional magnetic resonance imaging (fMRI) (Figures $1 \mathrm{~A} \& \mathrm{~B}$ ). The twentyfour (24) clips were evenly divided into positive, negative, and neutral valence categories.

Positive and negative clips were sampled from popular children's movies (e.g., classic movies such as The Wizard of $\mathrm{Oz}$ and Disney movies such as Rio and Up), such that each movie provided both a positive and negative clip for the stimuli set. Two films were live action (The Wizard of Oz, Shark Boy and Lava Girl) while the remaining six were animated (Anastasia, Lion King, Little Mermaid, Open Season, Rio, Up). The average amount of time participants spent viewing positive (253 s) and negative content (256 s) was approximately balanced. Positive and negative clips did not significantly differ in the total time $[t(14)=-0.67, p=0.51]$ or average time $[t(14)=-0.67, p=0.51]$ that faces were present on screen, so as to balance the presence of social stimuli between the two valenced conditions (Karim \& Perlman, 2017). Affective development is closely associated with sociality, as social experiences and information are nearly ubiquitously cited in the emotional development literature as a medium by which children build upon their understanding of affective, and more specifically, emotional, representations (e.g., family unit: Dunn et al., 1991, facial expressions: narratives: Pons et al., 2003). Thus, utilizing film clips containing socially relevant information balanced between valenced conditions may represent a more ecologically valid way of eliciting emotion representations than using stimuli devoid of social content.

Independent raters also coded the valence of each video second by second, such that seconds of positive affect (e.g., smiles, cheering, etc.) received a score of 1 , seconds 
of negative affect (e.g., anger, physical or verbal outbursts, etc.) received a score of -1 , and seconds lacking a clearly valenced emotion (i.e., not containing elements of previously defined positive/negative cues) received a score of 0 . As should be expected, positive and negative clips significantly differed in emotional valence $[t(14)=16.88, p<$ 0.001], with positive clips receiving an average second-by-second affective score of 0.89 and negative clips receiving an average affect score of -0.76 . There we no significant differences in the absolute value of these scores by valence $[t(14)=1.38, p=0.19]$, suggesting positive and negative clips were appropriately matched in time spent displaying categorically congruent valenced information (Karim \& Perlman, 2017). Neutral films were sourced from nature documentaries, used animals or plants as the focal targets, and included background music to mirror that of their affectively valenced counterparts. Participants were surveyed on their familiarity with each film and no differences were observed between adults and children in total familiarity scores $[t(57)=$ $-0.15, p=0.89]$ or average familiarity scores $[t(57)=0.27, p=0.79]$ (Karim \& Perlman, 2017).

Individual film clips ranged from 19 to $46 \mathrm{~s}(M=31.1 \mathrm{~s})$ with a jittered black screen interstimulus interval (ISI) of 6 to 12 seconds, resulting in a total viewing time of 17 mins (1020 s). To minimize the effects of emotional carryover, video clips were randomized into three orders and assigned to participants at random.

All participants completed a mock scanning session prior to data collection during which they were trained to remain motionless via a monitoring system that provided visual and auditory feedback. Participants also completed a short practice version of the task containing clips not used during primary data collection. During data collection, 
participants were reminded to remain motionless and asked to "watch the movies as they normally would", with no further instructions provided. Exposure was followed by a short attention quiz, in which a single still frame was displayed and participants had to determine if it was pulled from a clip they just watched or a decoy image. Accuracy was sufficiently high for both children $[M=97.9 \%, S D=3.3 \%]$ and adults $[M=92.9 \%, S D=$ 7.9\%] (Karim \& Perlman, 2017).

\subsection{Calculating Interrater Reliability of Stimuli}

Media content is often subjective, and, in confirming agreement on the constructs represented in the content, a Krippendorff's alpha (Krippendorff, 2004; Lombard et al., 2002) is a common statistical comparison test used by media scholars to assess content constancy (Lombard, 2013; Lombard et al., 2002). To assess inter-rater agreement of video category classification, three undergraduate research assistants (uninformed about this analysis or hypothesis) coded the videos as either positive, negative, or neutral in affective valence. Hayes' SPSS Macro KALPHA was used to compute Krippendorff's alpha (http://afhayes.com/spss-sas-and-r-macros-and-code.html) for interrater agreement of affective valence ( $a=.91[\mathrm{Cl}: .83, .97])$. Based on these criteria, the stimuli were deemed as constant in terms of the media representations of positive, negative, and neutral stimuli categorization.

\subsection{Data Acquisition}

This data acquisition is also outlined similarly in Karim \& Perlman (2017). MRI images were collected using a $3.0 \mathrm{~T}$ Siemens Trio scanner with a 12-channel parallel 
receive head coil. Structural images were obtained through a T-1 weighted MP-RAGE sequence where 175 sagittal (whole-brain) slices were acquired. Functional whole brain blood oxygen level dependent (BOLD) images were acquired in a sagittal left-to-right pattern, with the exception of a portion of the middle/superior temporal cortex within both hemispheres $\left(\mathrm{TR}=2,000 \mathrm{~ms}, \mathrm{TE}=30 \mathrm{~ms}\right.$, flip angle $(\mathrm{FA})=90^{\circ}, \mathrm{FOV}=256 \mathrm{~mm}$, matrix size $64 \times 64$, voxel size $4 \times 4 \times 4 \mathrm{~mm}$ ). Using a gradient echo EPI (echo-planar imaging) sequence, five-hundred and ten (510) successive brain volumes were captured over seventeen minutes and six seconds (17m06s).

\subsection{Pre-Processing}

Structural and functional data was preprocessed to minimize the effects of head motion. Data was high-pass filtered using FEAT (fMRI Expert Analysis Tool) and skull stripping was performed using BET (Brain Extraction Tool). Both tools are included in FSL (v5.0; https://fsl.fmrib.ox.ac.uk) (Jenkinson et al., 2012). Functional data were registered to anatomical images and nonlinearly warped to MNI standard space. We identified head motion and noise-related factors by using timeseries data extracted from white matter and CSF, six head motion parameters, and their first derivatives to calculate and threshold metric values of how each time point was motion-affected. Additionally, individual TRs were identified and regressed out based on excessive head motion. Excessive head motion TRs were identified using the FSL Motion Outlier tool, which defines outlier thresholds as the 75 th percentile plus 1.5 times the interquartile range. If more than $15 \%$ of TRs were considered outliers or if head motion values for any of the three rotations were greater than $1.5 \mathrm{~mm}$, participants were excluded from analyses. 


\subsection{Regions of Interest}

We captured vmPFC data using an activation-centered mask with a $10 \mathrm{~mm}$ diameter isotropic kernel. Central MNI coordinates [X, Y, Z: 2, 46, -8] for the mask were identified in a meta-analysis by Barta, McGuire, and Kable (2013) as the most common center of consistent vmPFC activation during studies of subjective valuation and primary incentives. Amygdala and NAcc masks were taken from the Harvard-Oxford subcortical atlas (Makris et al., 2006; Frazier et al. 2005; Desikan et al., 2006; Goldstein et al., 2007). Masks were applied to all regions of interest (ROIs), such that data from voxels beyond the bounds of the masks were excluded, and the included voxels were aligned with functional volumes. Amygdala and NAcc ROls were thresholded at $50 \%$. All masks were broadly defined in $\mathrm{MNI}$ space, applied to ROls, and ROls were transformed into subject native space using non-linear estimations (FNIRT tool in FSL). Transformations were visually inspected for accuracy. Mask placements are visualized in Figure 2.

\subsection{Statistical Analyses}

For each participant, we ran a General Linear Model (GLM) which had 24 regressors of interest, one for each positive, negative, and neutral video clip. From these individual participant GLMs, we then extracted the activity for each voxel within each of our three ROIs (AMY, NAcc, and vmPFC) for each of the video clips. The value of each voxel represents the average change in activation while passively viewing the video stimulus relative to baseline fixation cross measurements. To measure representational similarity within each of our three ROls, the individual voxels contained within each 
participant's GLM were aligned by MNI coordinates, such that the same spaces were being compared to one another within-participant across clips.

Next, we used representational similarity analysis (RSA) to calculate our dependent measure. Pairwise complete observations of activity in each voxel within each ROI for each video clip were correlated with one another using the Spearman rank-order correlation method for non-parametric data. These correlation coefficients represent how similar the pattern of activation is within a given ROI between two different stimuli. In theory, the more similar the pattern of activation is, the more similarly the two stimuli are being represented by a neural structure (for a full review, see Popal et al., 2019). Pairwise comparisons were performed across movie, but within valenced movie clips for each participant. For example, a positively valenced movie clip from Lion King was compared to a positively valenced movie clip from The Little Mermaid. This system produces an equal number of correlations in three within-valence categories: positive-to-positive comparisons, negative-to-negative comparisons, and neutral-to-neutral comparisons. It is important to note that our positively valenced Lion King clip, for example, could not reliably be compared to Lion King's own negatively-valenced counterpart, as any two clips from the same source might demonstrate a high degree of representational similarity due to superficial or non-affective characteristics (e.g., common characters, audio motifs, stylistic overlap, etc.). This non-affective similarity would confound with any affective pattern similarity that was observed and would obscure the interpretation of our results. As such, only inter-movie comparisons were considered. Fisher's Z-Transformation was applied to all correlations before proceeding. Correlating the extracted GLM data from our 
24 movie clips produced 28 correlative coefficients for each within-valence comparison per participant per ROI.

We were primarily concerned with exploring three effects: 1.) the interaction of age and $\mathrm{ROI}$, such that adults and children may show greater similarity to one another in subcortical affective representation relative to vmPFC representation, 2.) a contrast of valence within age group, or whether children demonstrate measurably greater representational similarity relative to adults towards valenced stimuli (i.e., positive and negative), and 3.) the interaction of age and valence, or whether we'd find that children demonstrate a greater discrepancy in negative and positive affective representational similarity than do adults.

To accurately represent age group as a between subject fixed effect and $\mathrm{ROI}$ and valence category as within subject fixed effects, data were analyzed using a 3 (ROI: AMY, NAcc, vmPFC) $\times 2$ (age group: children, adults) $\times 3$ (valence type: positive, negative, neutral) Mixed Effects ANOVA. Results from our ANOVA were followed with Bonferroniadjusted post-hoc contrasts to further elucidate the relationship among our effects. Analyses were performed using the $\mathrm{R}$ statistical programming language (v4.0.3; http://www.R-project.org/) in conjunction with the Integrated Development Environment, RStudio (v1.3.1093; https://rstudio.com/)

Due to the extensively documented neurodevelopmental changes children experience in our age range (4 yrs $-10 \mathrm{yrs}$ ), there was some concern that while convenient, categorizing participants ages 4 to 10 into the same developmental category may conceal important variability within the sample (Gee et al., 2013). As a result, an additional analysis was performed to determine whether age predicted representational 
similarity values treating our Fisher's Z-transformed correlation values as a criterion variable in a multilevel model predicted by the fixed effects of age, measured as a continuous variable in months, and participant, as a random effect, with random intercepts and fixed slopes.

\subsection{Results}

Using multilevel regression, we failed to find predictive utility for age in months towards representational similarity among our child sample $(\beta=0.085$, se $=0.143, p>$ 0.05), lending further support to the categorical boundaries we had defined. This model failed to outperform a null model lacking fixed effects $(I C C=0.094)$.

Using a mixed effects ANOVA model adjusting for the random effect of participant, significant differences were measured in the interaction between ROI and Age Group $[F(2,11279)=10.13, p<0.001]$. Bonferroni adjusted post-hoc contrasts further illustrated that children demonstrated greater representational similarity in amygdala [t(3757) $=$ $\left.3.784, p_{\text {adj. }}<0.001\right], \operatorname{NAcc}\left[t(3638)=3.588, p_{\text {adj. }}<0.001\right]$, and $\operatorname{vmPFC}[t(3676)=7.901$, $\left.p_{\text {adj. }}<0.001\right]$ activation patterns relative to adults (Figure 3). Children also demonstrated differences in representational similarity between the amygdala and vmPFC $[t(3931)=-$ 7.300, $\left.p_{\text {adj. }}<0.001\right]$ and NAcc and vmPFC $\left[t(4188)=-4.569, p_{a d j .}<0.001\right]$, but not AMY and NAcc $\left[t(4013)=-2.361, p_{a d j}=0.468\right]$. No such ROI differences were observed in our adult sample [AMY-NAcc: $t(3036)=-1.465, p_{\text {adj. }}=1.000 ;$ AMY-vmPFC: $t(3004)=-1.341$, $p_{\text {adj. }}=1.000 ;$ NAcc-vmPFC: $\left.t(3357)=0.092, p_{\text {adj. }}=1.000\right]$. Interaction contrasts found that the differences between the adult amygdala and vmPFC to be different than that of the child amygdala and vmPFC $\left[t(7551)=-4.766, p_{\text {adj. }}<0.001\right]$, as well as between 
vmPFC and NAcc, $\left[t(7553)=3.511, p_{a d j .}<0.001\right]$, but no such differences were observed between the amygdala and NAcc $\left[t(7558)=-0.875, p_{\text {adj. }}=1.000\right]$. See Table 1 for additional ROI and Age Group contrast results.

Contrasts of valence within age group suggest that adults do demonstrate relatively less representational similarity in response to valenced stimuli $[t(7355)=-8.863$,

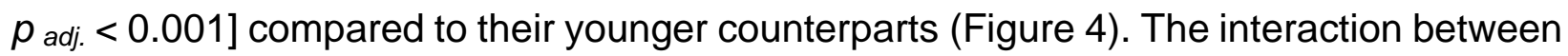
Age Group and Valence was also deemed significant $[F(2,11279)=10.74, p<0.001]$ with children showing greater positive $[t(3687)=3.872, p$ adj. $<0.001]$ and negative $\left[t(3660)=8.693, p_{\text {adj. }}<0.001\right]$, but not neutral $\left[t(3710)=2.938, p_{\text {adj. }}=0.078\right]$, representational similarity relative to adults. Similar to $\mathrm{ROI}$, adults did not differentiate among any valence categories [Pos-Neg: $t(3358)=0.727, p_{\text {adj. }}=1.000$; Pos-Neut: $t(3347)=1.470, p_{a d j}=1.000 ;$ Neg-Neut: $\left.t(3346)=0.720, p_{a d j}=1.000\right]$. Children, though, did show greater similarity for negative affective stimuli over both their positive $[t(4196)=$ -4.142, $\left.p_{\text {adj. }}<0.001\right]$ and neutral $\left[t(4197)=6.882, p_{\text {adj. }}<0.001\right]$ counterparts. Positive affective stimuli did not show greater similarity above that of neutral stimuli in children $\left[t(4192)=2.637, p_{\text {adj. }}=0.208\right]$. The difference between valenced and non-valenced stimuli was significant in children $\left[t(4306)=5.504, p_{\text {adj. }}<0.001\right]$, but not adults $[t(3542)$ $\left.=1.277, p_{\text {adj. }}=1.000\right]$. See Table 2 for additional Valence \& Age Group contrast results, and Table 3 for ANOVA results.

\subsection{Discussion}

This study represents a first attempt to compare developmental differences between adults and children in prefrontal and subcortical region cognitive representations 
of affective information. Based on extant literature, we expected children to demonstrate a greater discrepancy in pattern activation between the vmPFC and subcortical structures relative to adults. Between childhood and early adulthood, we witnessed a marked decrease in affectively valenced pattern similarity. Furthermore, valence-specific differences and region-specific differences that were present in children, having demonstrated greater similarity for negative stimuli compared to positive and within the vmPFC relative to subcortical structures (AMY \& NAcc), were absent in our adult sample. Taken together, these results may suggest that affective representations decrease in pattern similarity over normative development; though, longitudinal designs may be better suited to demonstrate a casual trajectory. With an emphasis on the notable representational differences in vmPFC development, we interpret these results to suggest that people may experience a maturation from visceral affective responses which merely assess how evocative an affective experience is, to more evaluative analyses which modulate affective responses between childhood and adulthood. This supposition is supplemented by extant findings from the neurobehavioral literature.

For example, activation of the amygdala has demonstrated a consistent positive association with affective physiological markers, such as heart rate variability (Wei et al., 2018) and perspiration (Asahina et al., 2003), as well as reports of affective intensity (Bonnet et al. 2015). Activity changes in the NAcc have coincided with reports of valenced affective intensity, as well (Knutson \& Greer, 2008). For both the VS and amygdala, the extent to which their affective contributions can be modulated seems to be a consequence of their functional connectivity to medial prefrontal regions (Wei et al., 2018; Sakaki et al., 2016; Cohen et al., 2008). Univariate methods also support potential differences in NAcc 
contributions to affect processing across age, and the increased risk of depression upon alterations in NAcc activity emphasizes the importance of this region for adequate emotional development (Monk et al., 2008). In addition to univariate interpretations, multivariate studies have disentangled discrete emotional categories from patterns of activity across several neural regions (Camacho et al., 2019; Saarimaki et al., 2016) and, more specifically, within the vmPFC (Kragel \& LaBar, 2015, 2016). When disentangling multivariate patterns for discrete emotional categories, the vmPFC, in addition to the inferior lateral PFC, contributed most to how well the neural signals could classify each emotion (Saarimaki et al., 2016), resonating with an established body of work tying the vmPFC to emotion (Hiser \& Koenigs, 2018; Greene, 2007; Moll \& de Oliveira-Souza, 2007; Winecoff et al., 2013; Yang et al., 2018).

While the vmPFC likely performs some affective processing in and of itself, it may also regulate affective processing in the NAcc and amygdala (Hiser \& Koenigs, 2018). The development of functional connectivity between the medial prefrontal cortex (mPFC) and amygdala (Gee et al., 2013; Bouwmeester et al., 2002a) may contribute to greater control over these physiological and experiential affective responses, which may also contribute to a greater variety, allowing for greater nuance, in affective representation.

Our results finding age-specificity in pattern similarity is in line with developmental perspectives of the VmPFC's role in emotional processing and aligns with past work demonstrating distinctions between this area's function across age. For instance, Silvers et al., (2017) found age-related decreases in vmPFC response to emotional photos, with larger degrees of vmPFC involvement found among younger participants relative to older ones. While mPFC-VS resting state functional connectivity demonstrates a positive 
relationship from childhood through early adulthood, whether connectivity increases with age (Di Martino et al., 2008, 2011) or remains stable through development (Fareri et al., 2015; Greene et al., 2014) is debated. The magnitude of task-based functional connectivity between mPFC and VS also appears to be variable dependent upon the taskbased context (Richards et al., 2013), though, age-related linear increases have been observed for positive incentives (van der Bos et al., 2012). Regardless of potential changes in connectivity, it may be the case that the connection between VS and VmPFC serves a stimulus evaluation role (Fareri et al., 2015; Bartra et al., 2013; Salzman et al., 2007) which may modulate value-related signals relevant to affectively valenced stimuli. Taken together, a potential interpretation of our findings is that, in light of the region's role in processing of emotional stimuli, the pattern and response similarities we find in children may signal their shared, relatively-limited experience of the vast array of potential affectively-relevant experiences, while adults respond more divergently to novel affectively-valenced information by referencing a wider berth of past evaluations.

The cognitive literature also presents at least a few mechanisms by which representations may grow more dissimilar with age. Appraisal theories of emotion broadly posit that emotions are elicited by or are emergent phenomena from evaluations of events and circumstances (Roseman \& Smith, 2001; Ortony, Clore, \& Collins, 1988; Clore \& Ortony, 2008). These evaluations may be colored by the biases and information individuals already possess. It may be the case that the greater potential for experiential variance inherent to having had lived longer may add nuance or variation to adult representations relative to children. Similar mechanisms have been theorized by other researchers (e.g., Pons et al., 2003) and such a postulation fits nicely with rational 
constructivist-related theories of emotional development, in which humans start with proto-conceptual primitives to emotion which mature over time due to language and symbol learning, Bayesian inductive learning, and constructive thinking mechanisms (Hoemann, Xu, \& Barrett, 2019; For a review, see Fedyk \& Xu, 2018). Relatedly, our ability to consider the multidimensionality of affect-related concepts improves with age as well, which could logically lead to greater idiosyncratic processing. This may speak to our age-related valence findings, as adults likely defaulted to representing emotional information continuously, rather than strictly categorically (See Satpute et al., 2016). It's relevant to cite Nook and colleagues again, as they had found that affective complexities like valence and arousal were a function of age (Nook et al., 2017; 2018). As such, our conceptions of affective experiences may evolve over development from notions relatively faithful to valence-general lines (i.e., "good", "bad") to representing a more nuanced, multidimensional understanding of affective experiences.

While adults did demonstrate lower levels of similarity in response to valence than children, it's notable that the correlation was not non-existent. As a result, valence likely still plays a role in shaping some aspects of decision-making and behavior and may explain the findings like those suggesting greater homogeneity in response to norm violations of negative affect than positive affect, with targets who express positive or neutral responses to negatively perceived stimuli to be judged as less authentic (Krumhuber \& Manstead, 2009), socially appropriate, and less liked (Ansfield, 2007), as well as punished more harshly than incongruent responses to differently valenced stimuli (Szezurek, Monin, and Gross, 2012). These findings support previous suppositions regarding an information value asymmetry between positive and negative affective 
experiences, as negative information may signal a need for adjustment to avoid detrimental consequences (O'toole et al., 2020; Pratto \& John, 1991).

Although we can make guesses, we do not possess the statistical resolution nor the appropriate research design to write with any certainty what mechanism or mechanisms may be at play here and future work relating differences in representational similarity to the accrual and modeling of affective experience is needed.

\subsection{Study Limitations}

First, some logistical concerns relevant to human neuroimaging in a developmental population must be highlighted. Our effective sample size of 25 children and 20 adults is small for a study spanning such a large age range. Related to our limited sample is the disproportionately greater frequency of head motion artifacts commonly produced when scanning children (Greene, Black, \& Schlaggar, 2016), which resulted in 11 children being excluded from our analyses (as compared to only 1 adult). There is some concern regarding comparability of neural structures and responses over development. Children do demonstrate greater BOLD signal response both at rest and during neural activity relative to adolescents and adults, although this difference is likely non-significant following normalization (Moses et al., 2014; Bray, 2017). Additionally, due to structural maturations through development, the use neural atlases not specialized for children (e.g., Harvard-Oxford) may depreciate in utility, though, the extent is unclear.

While our results suggest a number of differences in affective representation between children and adults, it is difficult to conclude with certainty exactly what implications this similarity has for cognition and behavior without additional 
measurements. Although we can make inferences, our RSA analysis is incapable of commenting with any certainty as to the contents of representations, or in what ways they are similar or dissimilar. Our interpretations of these results are based upon the extant literature exploring the functions of the amygdala, NAcc, and vmPFC in similar experimental contexts, but the debate as to the precise functions of each is still widely contested. For example, meta-analyses suggest that the posterior vmPFC, for example, differentially responds to emotion, while the rostral and central vmPFC demonstrate increased activation during social processing and valuation judgments, respectively (Hiser \& Koenigs, 2018), which may suggest a need for more precise anatomicallydefined masking to explore questions of affectivity in the vmPFC.

To address concerns that observed patterns may be in response to non-affective characteristics of the stimuli, we compared pattern similarity of affectively valenced video pairs to pairwise comparisons of our neutral stimuli set. Representational similarity was greater for affective stimuli than non-affective stimuli in children $\left[t(4306)=5.504, p_{\text {adj. }}<\right.$ $0.001]$, but not adults $\left[t(3542)=1.277, p_{\text {adj. }}=1.000\right]$. This was surprising, as it could suggest valence to be too simple of a metric by which to classify neural activation patterns in adults. However, it is more likely that there were characteristics of our neutral video set which limit their utility as ideal controls. While valenced stimuli consisted of both animated and live-action videos, our neutral videos were strictly live-action videos, which may have influenced how participants evaluated them. Similarly, the presence of socially relevant stimuli (i.e., use of language, humans, anthropomorphized animals) were not balanced between valenced and neutral videos. Additionally, while categorical coherence was assessed twice for valenced videos and once for neutral videos by independent raters, 
the subjective evaluations or interpretations of individual participants in response to the stimuli may have varied more than anticipated. This could be especially problematic with such a small dataset. As such, any differences observed between valenced and nonvalenced (i.e. neutral) representations should especially be skeptically considered in the absence of replication with more suitable controls.

An additional limitation is the lack of resolution of emotional classifications among our affective observations. Although affective representations like those we'd focused on this study may relate to representations of emotions, they are not synonymous, and emotions which might typically be considered categorically congruent in terms of affect can vary dramatically in terms of expression, experience, and physiology. For example, studies that have compared activation patterns of different "negatively valence" emotions have found dramatic differences, especially within the basal ganglia and medial PFC (Kassam, Markey, Cherkassky, Loewenstein, \& Just, et al., 2013). Furthermore, expression, experience, and physiology of the same emotions can vary dramatically from person to person (See Clore \& Ortony, 2013) and culture to culture (Ma, Tamir, \& Miyamoto, 2018). Our investigation lacked the statistical power to analyze affective classifications at a more granular level (i.e., emotions), and, as such, its ability to comment towards, perhaps, a more ecologically-valid phenomena is depreciated.

\subsection{Conclusions}

The present study found differences in how similarly children and adults represent affective stimuli within the amygdala, NAcc, and vmPFC, as well as by valence. The representation of affect in subcortical structures, like the amygdala and NAcc, may 
change relatively less across the lifespan than frontal regions, such as the vmPFC, which may be indicative of a maturation from passive assessment to active engagement with or modulation of affectively-relevant experiences. Although it may be natural as an adult to pine for the relative simplicity with which we assessed our childhood experiences, our findings suggest these might be necessary trade-offs in the development of mature, nuanced understandings of our emotional experiences. 


\section{Declaration of interests}

The authors declare that they have no known competing financial interests or personal relationships that could have appeared to influence the work reported in this paper.

\section{Funding Statement}

Funding for data collection was provided to Susan B. Perlman and sponsored by National institutes of Health; Contract grant number: K01 MH094467.

\section{Research Data Statement}

This research data and its associated scripts have been made available at https://github.com/Wjpmitchell3/Developmental-RSA-Project

\section{Credit Author Statement}

William J. Mitchell: Conceptualization, Methodology, Formal analysis, Data Curation, Writing - Original Draft, Visualization Lindsey J. Tepfer: Conceptualization, Methodology, Formal analysis, Writing - Original Draft, Visualization Nicole M. Henninger: Conceptualization, Methodology, Formal analysis, Writing - Original Draft Vishnu P. Murty: Conceptualization, Methodology, Resources, Writing - Review \& Editing, Supervision, Project administration Chelsea Helion: Conceptualization, Writing

- Review \& Editing, Supervision Susan B. Perlman: Software, Investigation, Resources, Data Curation, Writing - Review \& Editing 


\section{References:}

Ansfield, M. E. (2007). Smiling when distressed: When a Smile Is a Frown Turned Upside Down. Personality and Social Psychology Bulletin, 33(6), 763-775. https://doi.org/10.1177/0146167206297398

Asahina, M., Suzuki, A., Mori, M., Kanesaka, T., \& Hattori, T. (2003). Emotional sweating response in a patient with bilateral amygdala damage. International Journal of Psychophysiology, 47(1), 87-93. https://doi.org/10.1016/S0167-8760(02)00123-X

Barrett, L. F. (2006). Solving the emotion paradox: Categorization and the experience of emotion. Personality and Social Psychology Review, 10(1), 20-46. https://doi.org/10.1207/s15327957pspr100122

Barrett, L. F. (2016). The theory of constructed emotion: An active inference account of interoception and categorization. Social Cognitive and Affective Neuroscience, 12(1), 1-23. https://doi.org/10.1093/scan/nsw154

Bartra, O., McGuire, J. T., \& Kable, J. W. (2013). The valuation system: A coordinatebased meta-analysis of BOLD fMRI experiments examining neural correlates of subjective value. Neurolmage, $76,412-427$.

\section{https://doi.org/10.1016/j.neuroimage.2013.02.063}

Baumeister, R. F., Bratslavsky, E., Finkenauer, C., \& Vohs, K. D. (2001). Bad is stronger than good. Review of General Psychology, 5(4), 323-370. https://doi.org/10.1037/1089-2680.5.4.323

Bhanji, J., Smith, D. V., \& Delgado, M. (2019). A brief anatomical sketch of human ventromedial prefrontal cortex [Preprint]. PsyArXiv. https://doi.org/10.31234/osf.io/zdt7f 
Bonnet, L., Comte, A., Tatu, L., Millot, J.-L., Moulin, T., \& Medeiros de Bustos, E. (2015). The role of the amygdala in the perception of positive emotions: An "intensity detector." Frontiers in Behavioral Neuroscience, 9. https://doi.org/10.3389/fnbeh.2015.00178

Bouwmeester, H., Smits, K., \& Van Ree, J. M. (2002). Neonatal development of projections to the basolateral amygdala from prefrontal and thalamic structures in rat. The Journal of Comparative Neurology, 450(3), 241-255. https://doi.org/10.1002/cne.10321

Bouwmeester, H., Wolterink, G., \& Van Ree, J. M. (2002). Neonatal development of projections from the basolateral amygdala to prefrontal, striatal, and thalamic structures in the rat. The Journal of Comparative Neurology, 442(3), 239-249. https://doi.org/10.1002/cne.10084

Bray, S. (2017). Age-associated patterns in gray matter volume, cerebral perfusion and BOLD oscillations in children and adolescents: Multimodal imaging of brain development. Human Brain Mapping, 38(5), 2398-2407. https://doi.org/10.1002/hbm.23526

Camacho, M. C., Karim, H. T., \& Perlman, S. B. (2019). Neural architecture supporting active emotion processing in children: A multivariate approach. Neurolmage, 188, 171-180. https://doi.org/10.1016/j.neuroimage.2018.12.013

Clore, G. L., \& Ortony, A. (2008). Appraisal theories: How cognition shapes affect into emotion. In Handbook of emotions, 3rd ed. (pp. 628-642). The Guilford Press. 
Clore, G. L., \& Ortony, A. (2013). Psychological construction in the OCC model of emotion. Emotion Review, 5(4), 335-343. https://doi.org/10.1177/1754073913489751

Cohen, M. X., Schoene-Bake, J.-C., Elger, C. E., \& Weber, B. (2009). Connectivitybased segregation of the human striatum predicts personality characteristics. Nature Neuroscience, 12(1), 32-34. https://doi.org/10.1038/nn.2228

Davis, M., \& Whalen, P. J. (2001). The amygdala: Vigilance and emotion. Molecular Psychiatry, 6(1), 13-34. https://doi.org/10.1038/sj.mp.4000812

Desikan, R. S., Fischl, B., Quinn, B. T., Dickerson, B. C., Blacker, D., Buckner, R. L., Dale, A. M., Maguire, R. P., Hyman, B. T., Albert, M. S., \& Killiany, R. J. (2006). An automated labeling system for subdividing the human cerebral cortex on MRI scans into gyral based regions of interest. Neuroimage, 31(3), 968-980. https://doi.org/10.1016/j.neuroimage.2006.01.021

Di Martino, A., Scheres, A., Margulies, D. S., Kelly, A. M. C., Uddin, L. Q., Shehzad, Z., Biswal, B., Walters, J. R., Castellanos, F. X., \& Milham, M. P. (2008). Functional connectivity of human striatum: A resting state fMRI study. Cerebral Cortex, 18(12), 2735-2747. https://doi.org/10.1093/cercor/bhn041

Di Martino, Adriana, Kelly, C., Grzadzinski, R., Zuo, X.-N., Mennes, M., Mairena, M. A., Lord, C., Castellanos, F. X., \& Milham, M. P. (2011). Aberrant striatal functional connectivity in children with autism. Biological Psychiatry, 69(9), 847-856. https://doi.org/10.1016/j.biopsych.2010.10.029

Dimsdale-Zucker, H. R., \& Ranganath, C. (2018). Chapter 27 - Representational similarity analyses: A practical guide for functional MRI applications. In D. Manahan- 
Vaughan (Ed.), Handbook of Behavioral Neuroscience (Vol. 28, pp. 509-525).

Elsevier. https://doi.org/10.1016/B978-0-12-812028-6.00027-6

Dunn, J., Brown, J., \& Beardsall, L. (1991). Family talk about feeling states and children's later understanding of others' emotions. Developmental Psychology, 27(3), 448-455. https://doi.org/10.1037/0012-1649.27.3.448

Fabes, R. A., Eisenberg, N., Nyman, M., \& Michealieu, Q. (1991). Children's appraisals of others' spontaneous emotional reactions. Developmental Psychology, 27(5), 858866. https://doi.org/10.1037/0012-1649.27.5.858

Fareri, D. S., Gabard-Durnam, L., Goff, B., Flannery, J., Gee, D. G., Lumian, D. S., Caldera, C., \& Tottenham, N. (2015). Normative development of ventral striatal resting state connectivity in humans. Neurolmage, 118, 422-437. https://doi.org/10.1016/i.neuroimage.2015.06.022

Fedyk, M., \& Xu, F. (2018). The epistemology of rational constructivism. Review of Philosophy and Psychology, 9(2), 343-362. https://doi.org/10.1007/s13164-017$\underline{0372-1}$

Frazier, J. A., Chiu, S., Breeze, J. L., Makris, N., Lange, N., Kennedy, D. N., Herbert, M. R., Bent, E. K., Koneru, V. K., Hodge, S. M., Rauch, S. L., Grant, P. E., Cohen, B. M., Seidman, L. J., Caviness, V. S., \& Biederman, J. (2005). Structural brain magnetic resonance imaging of limbic and thalamic volumes in pediatric bipolar disorder. American Journal of Psychiatry, 162(7), 1256-1265. https://doi.org/10.1176/appi.ajp.162.7.1256

Gabard-Durnam, L. J., Flannery, J., Goff, B., Gee, D. G., Humphreys, K. L., Telzer, E., Hare, T., \& Tottenham, N. (2014). The development of human amygdala functional 
connectivity at rest from 4 to 23years: A cross-sectional study. Neurolmage, 95, 193-207. https://doi.org/10.1016/j.neuroimage.2014.03.038

Gee, D. G., Humphreys, K. L., Flannery, J., Goff, B., Telzer, E. H., Shapiro, M., Hare, T. A., Bookheimer, S. Y., \& Tottenham, N. (2013). A developmental shift from positive to negative connectivity in human amygdala-prefrontal circuitry. Journal of Neuroscience, 33(10), 4584-4593. https://doi.org/10.1523/JNEUROSCI.3446$\underline{12.2013}$

Goldstein, J. M., Seidman, L. J., Makris, N., Ahern, T., O’Brien, L. M., Caviness, V. S., Kennedy, D. N., Faraone, S. V., \& Tsuang, M. T. (2007). Hypothalamic abnormalities in schizophrenia: Sex effects and genetic vulnerability. Biological Psychiatry, 61(8), 935-945. https://doi.org/10.1016/j.biopsych.2006.06.027

Greene, D. J., Laumann, T. O., Dubis, J. W., Innen, S. K., Neta, M., Power, J. D., Pruett, J. R., Black, K. J., \& Schlaggar, B. L. (2014). Developmental changes in the organization of functional connections between the basal ganglia and cerebral cortex. Journal of Neuroscience, 34(17), 5842-5854. https://doi.org/10.1523/JNEUROSCI.3069-13.2014

Greene, Deanna J., Black, K. J., \& Schlaggar, B. L. (2016). Considerations for MRI study design and implementation in pediatric and clinical populations.

Developmental Cognitive Neuroscience, 18, 101-112. https://doi.org/10.1016/j.den.2015.12.005

Greene, J. D. (2007). Why are VMPFC patients more utilitarian? A dual-process theory of moral judgment explains. Trends in Cognitive Sciences, 11(8), 322-323. https://doi.org/10.1016/j.tics.2007.06.004 
Haxby, J. V., Connolly, A. C., \& Guntupalli, J. S. (2014). Decoding neural representational spaces using multivariate pattern analysis. Annual Review of Neuroscience, 37, 435-456. https://doi.org/10.1146/annurev-neuro-062012-170325

Hayes, A. F. (2020). SPSS, SAS and R Macros and Code. http://afhayes.com/spss-sasand-r-macros-and-code.html

Hiser, J., \& Koenigs, M. (2018). The multifaceted role of the ventromedial prefrontal cortex in emotion, decision making, social cognition, and psychopathology. Biological Psychiatry, 83(8), 638-647. https://doi.org/10.1016/j.biopsych.2017.10.030

Hoemann, K., Xu, F., \& Barrett, L. F. (2019). Emotion words, emotion concepts, and emotional development in children: A constructionist hypothesis. Developmental Psychology, 55(9), 1830-1849. https://doi.org/10.1037/dev0000686

Jalbrzikowski, M., Larsen, B., Hallquist, M. N., Foran, W., Calabro, F., \& Luna, B. (2017). Development of white matter microstructure and intrinsic functional connectivity between the amygdala and ventromedial prefrontal cortex: Associations with anxiety and depression. Biological Psychiatry, 82(7), 511-521. https://doi.org/10.1016/j.biopsych.2017.01.008

Jenkinson, M., Beckmann, C. F., Behrens, T. E. J., Woolrich, M. W., \& Smith, S. M. (2012). FSL. Neurolmage, 62(2), 782-790. https://doi.org/10.1016/i.neuroimage.2011.09.015

Karim, H. T., \& Perlman, S. B. (2017). Neurodevelopmental maturation as a function of irritable temperament. Human Brain Mapping, 38(10), 5307-5321. https://doi.org/10.1002/hbm.23742 
Kassam, K. S., Markey, A. R., Cherkassky, V. L., Loewenstein, G., \& Just, A. (2013). Identifying emotions on the basis of neural activation. PLOS ONE, 8(6), 12. https://doi.org/10.1371/journal.pone.0066032

Knutson, B., \& Greer, S. M. (2008). Anticipatory affect: Neural correlates and consequences for choice. Philosophical Transactions of the Royal Society B:

Biological Sciences, 363(1511), 3771-3786. https://doi.org/10.1098/rstb.2008.0155

Kragel, P. A., \& LaBar, K. S. (2015). Multivariate neural biomarkers of emotional states are categorically distinct. Social Cognitive and Affective Neuroscience, 10(11), 1437-1448. https://doi.org/10.1093/scan/nsv032

Kragel, P. A., \& LaBar, K. S. (2016). Decoding the nature of emotion in the brain. Trends in Cognitive Sciences, 20(6), 444-455. https://doi.org/10.1016/.itics.2016.03.011

Kriegeskorte, N., Mur, M., \& Bandettini, P. (2008). Representational similarity analysisConnecting the branches of systems neuroscience. Frontiers in Systems Neuroscience, 2, 4. https://doi.org/10.3389/neuro.06.004.2008

Krippendorff, K. (2004). Reliability in content analysis: Some common misconceptions and recommendations. Human Communication Research, 30(3), 411-433. https://doi.org/10.1111/j.1468-2958.2004.tb00738.x

Krumhuber, E. G., \& Manstead, A. S. R. (2009). Can Duchenne smiles be feigned? New evidence on felt and false smiles. Emotion, 9(6), 807-820. https://doi.org/10.1037/a0017844 
Larson, R., Csikszentmihalyi, M., \& Graef, R. (1980). Mood variability and the psychosocial adjustment of adolescents. Journal of Youth and Adolescence, 9(6), 469-491. https://doi.org/10.1007/BF02089885

Levita, L., Hare, T. A., Voss, H. U., Glover, G., Ballon, D. J., \& Casey, B. J. (2009). The bivalent side of the nucleus accumbens. Neurolmage, 44(3), 1178-1187. https://doi.org/10.1016/j.neuroimage.2008.09.039

Lombard, M. (2012). Lessons learned from a research saga: An ambitious content analysis of television form. In The International Encyclopedia of Media Studies (pp. 303-318).

Lombard, Matthew, Snyder-Duch, J., \& Bracken, C. C. (2002). Content analysis in mass communication: Assessment and reporting of intercoder reliability. Human Communication Research, 28(4), 587-604. https://doi.org/10.1111/j.14682958.2002.tb00826.x

Ma, X., Tamir, M., \& Miyamoto, Y. (2018). A socio-cultural instrumental approach to emotion regulation: Culture and the regulation of positive emotions. Emotion, 18(1), 138-152. https://doi.org/10.1037/emo0000315

Makris, N., Goldstein, J. M., Kennedy, D., Hodge, S. M., Caviness, V. S., Faraone, S. V., Tsuang, M. T., \& Seidman, L. J. (2006). Decreased volume of left and total anterior insular lobule in schizophrenia. Schizophrenia Research, 83(2-3), 155-171. https://doi.org/10.1016/i.schres.2005.11.020

Moll, J., \& de Oliveira-Souza, R. (2007). Moral judgments, emotions and the utilitarian brain. Trends in Cognitive Sciences, 11(8), 3. https://doi.org/10.1016/j.tics.2007.06.001 
Monk, C. S., Klein, R. G., Telzer, E. H., Schroth, E. A., Mannuzza, S., Moulton, J. L., Guardino, M., Masten, C. L., McClure-Tone, E. B., Fromm, S., Blair, R. J., Pine, D. S., \& Ernst, M. (2008). Amygdala and nucleus accumbens activation to emotional facial expressions in children and adolescents at risk for major depression. American Journal of Psychiatry, 165(1), 90-98.

\section{https://doi.org/10.1176/appi.ajp.2007.06111917}

Moses, P., DiNino, M., Hernandez, L., \& Liu, T. T. (2014). Developmental changes in resting and functional cerebral blood flow and their relationship to the BOLD response: CBF and BOLD Responses in Children. Human Brain Mapping, 35(7), 3188-3198. https://doi.org/10.1002/hbm.22394

Noftle, E. E., \& Fleeson, W. (2010). Age differences in big five behavior averages and variabilities across the adult life span: Moving beyond retrospective, global summary accounts of personality. Psychology and Aging, 25(1), 95-107. https://doi.org/10.1037/a0018199

Nook, E. C., Sasse, S. F., Lambert, H. K., McLaughlin, K. A., \& Somerville, L. H. (2017). Increasing verbal knowledge mediates development of multidimensional emotion representations. Nature Human Behaviour, 1(12), 881-889. https://doi.org/10.1038/s41562-017-0238-7

Nook, E. C., Sasse, S. F., Lambert, H. K., McLaughlin, K. A., \& Somerville, L. H. (2018). The nonlinear development of emotion differentiation: Granular emotional experience is low in adolescence. Psychological Science, 29(8), 1346-1357. https://doi.org/10.1177/0956797618773357 
Ortony, A., Clore, G. L., \& Collins, A. (1988). The Cognitive Structure of Emotions. Cambridge University Press. https://doi.org/10.1017/CBO9780511571299

O’Toole, M. S., Renna, Megan. E., Elkjær, E., Mikkelsen, M. B., \& Mennin, D. S. (2020). A systematic review and meta-analysis of the association between complexity of emotion experience and behavioral adaptation. Emotion Review, 12(1), 23-38. https://doi.org/10.1177/1754073919876019

Perlman, S. B., \& Pelphrey, K. A. (2011). Developing connections for affective regulation: Age-related changes in emotional brain connectivity. Journal of Experimental Child Psychology, 108(3), 607-620.

https://doi.org/10.1016/j.jecp.2010.08.006

Pons, F., Harris, P. L., \& de Rosnay, M. (2004). Emotion comprehension between 3 and 11 years: Developmental periods and hierarchical organization. European Journal of Developmental Psychology, 1(2), 127-152. https://doi.org/10.1080/17405620344000022

Pons, F., Lawson, J., Harris, P. L., \& de Rosnay, M. (2003). Individual differences in children's emotion understanding: Effects of age and language. Scandinavian Journal of Psychology, 44(4), 347-353. https://doi.org/10.1111/1467-9450.00354

Popal, H. S., Wang, Y., \& Olson, I. R. (2019). A guide to representational similarity analysis for social neuroscience. Social Cognitive and Affective Neuroscience, 14(11), 1243-1253. https://doi.org/10.1093/scan/nsz099

Pratto, F., \& John, O. P. (1991). Automatic vigilance: The attention-grabbing power of negative social information. Journal off Personality and Social Psychology, 61(3), 380-291. https://doi.org/10.1037/0022-3514.61.3.380 
Richards, J. M., Plate, R. C., \& Ernst, M. (2013). A systematic review of fMRI reward paradigms used in studies of adolescents vs. adults: The impact of task design and implications for understanding neurodevelopment. Neuroscience \& Biobehavioral Reviews, 37(5), 976-991. https://doi.org/10.1016/j.neubiorev.2013.03.004

Roseman, I. J., \& Smith, C. S. (2001). Appraisal theory: Overview, assumptions, varieties, controversies. In K. R. Scherer, A. Schorr, \& T. Johnstone (Eds.), Appraisal Processes in Emotion: Theories, methods, research (pp. 3-19). Oxford University Press.

Rosnay, M. D., \& Harris, P. L. (2002). Individual differences in children's understanding of emotion: The roles of attachment and language. Attachment \& Human Development, 4(1), 39-54. https://doi.org/10.1080/14616730210123139

Russell, J. A. (1980). A circumplex model of affect. Journal of Personality and Social Psychology, 39(6), 1161-1178. https://doi.org/10.1037/h0077714

Russell, J. A. (2003). Core affect and the psychological construction of emotion. Psychological Review, 110(1), 145-172. https://doi.org/10.1037/0033$\underline{295 X .110 .1 .145}$

Saarimäki, H., Gotsopoulos, A., Jääskeläinen, I. P., Lampinen, J., Vuilleumier, P., Hari, R., Sams, M., \& Nummenmaa, L. (2016). Discrete neural signatures of basic emotions. Cerebral Cortex, 26(6), 2563-2573. https://doi.org/10.1093/cercor/bhv086

Sakaki, M., Yoo, H. J., Nga, L., Lee, T.-H., Thayer, J. F., \& Mather, M. (2016). Heart rate variability is associated with amygdala functional connectivity with MPFC across younger and older adults. Neurolmage, 139, 44-52. https://doi.org/10.1016/j.neuroimage.2016.05.076 
Salzman, C. D., Paton, J. J., Belova, M. A., \& Morrison, S. E. (2007). Flexible neural representations of value in the primate brain. Annals of the New York Academy of Sciences, 1121(1), 336-354. https://doi.org/10.1196/annals.1401.034

Satpute, A. B., \& Lindquist, K. A. (2019). The default mode network's role in discrete emotion. Trends in Cognitive Sciences, 23(10), 851-864. https://doi.org/10.1016/j.tics.2019.07.003

Satpute, A. B., Nook, E. C., Narayanan, S., Shu, J., Weber, J., \& Ochsner, K. N. (2016). Emotions in "black and white" or shades of gray? How we think about emotion shapes our perception and neural representation of emotion. Psychological Science, 27(11), 1428-1442. https://doi.org/10.1177/0956797616661555

Silvers, J. A., Insel, C., Powers, A., Franz, P., Helion, C., Martin, R. E., Weber, J., Mischel, W., Casey, B. J., \& Ochsner, K. N. (2017). VIPFC-vmPFC-amygdala interactions underlie age-related differences in cognitive regulation of emotion. Cerebral Cortex, 27(7), 3502-3514. https://doiorg.libproxy.temple.edu/10.1093/cercor/bhw073

Silvers, J. A., McRae, K., Gabrieli, J. D. E., Gross, J. J., Remy, K. A., \& Ochsner, K. N. (2012). Age-related differences in emotional reactivity, regulation, and rejection sensitivity in adolescence. Emotion, 12(6), 1235-1247. https://doi.org/10.1037/a0028297

Szczurek, L., Monin, B., \& Gross, J. J. (2012). The stranger effect: The rejection of affective deviants. Psychological Science, 23(10), 1105-1111. https://doi.org/10.1177/0956797612445314 
van den Bos, W., van Dijk, E., \& Crone, E. A. (2012). Learning whom to trust in repeated social interactions: A developmental perspective. Group Processes \& Intergroup Relations, 15(2), 243-256. https://doi.org/10.1177/1368430211418698

Wei, L., Chen, H., \& Wu, G.-R. (2018). Structural covariance of the prefrontal-amygdala pathways associated with heart rate variability. Frontiers in Human Neuroscience, 12, 2. https://doi.org/10.3389/fnhum.2018.00002i

Wellman, H. M., Harris, P. L., Banerjee, M., \& Sinclair, A. (1995). Early understanding of emotion: Evidence from natural language. Cognition \& Emotion, 9(2-3), 117-149. https://doi.org/10.1080/02699939508409005

Widen, S. C. (2013). Children's interpretation of facial expressions: The long path from valence-based to specific discrete categories. Emotion Review, 5(1), 72-77. https://doi.org/10.1177/1754073912451492

Widen, S. C., \& Russell, J. A. (2003). A closer look at preschoolers' freely produced labels for facial expressions. Developmental Psychology, 39(1), 114-128. https://doi.org/10.1037/0012-1649.39.1.114

Widen, S. C., \& Russell, J. A. (2008). Children acquire emotion categories gradually. Cognitive Development, 23(2), 291-312. https://doi.org/10.1016/j.cogdev.2008.01.002

Widen, S. C., \& Russell, J. A. (2010). Differentiation in preschooler's categories of emotion. Emotion, 10(5), 651-661. https://doi.org/10.1037/a0019005

Winecoff, A., Clithero, J. A., Carter, R. M., Bergman, S. R., Wang, L., \& Huettel, S. A. (2013). Ventromedial prefrontal cortex encodes emotional value. Journal of 
Neuroscience, 33(27), 11032-10039. https://doi.org/10.1523/JNEUROSCI.4317-

$\underline{12.2013}$

Yang, X., Garcia, K. M., Jung, Y., Whitlow, C. T., McRae, K., \& Waugh, C. E. (2018). VmPFC activation during a stressor predicts positive emotions during stress recovery. Social Cognitive and Affective Neuroscience, 13(3), 256-268. https://doi.org/10.1093/scan/nsy012 
Tables

\begin{tabular}{|c|c|c|c|c|c|c|c|}
\hline Contrasts & Mean Diff. & SE & T Statistic & df & \multicolumn{3}{|c|}{ Bonferroni P } \\
\hline AMY, Child v. Adult & 0.037 & 0.010 & 3.784 & 3757 & $<$ & 0.001 & $* * *$ \\
\hline NAcc, Child v. Adult & 0.048 & 0.013 & 3.588 & 3638 & $<$ & 0.001 & $* * *$ \\
\hline vmPFC, Child v. Adult & 0.108 & 0.014 & 7.901 & 3676 & $<$ & 0.001 & $* * *$ \\
\hline Child, AMY v. NAcc & -0.028 & 0.011 & -2.361 & 4013 & & 0.468 & \\
\hline Child, $A M Y$ v. vmPFC & -0.087 & 0.012 & -7.300 & 3931 & $<$ & 0.001 & $* * *$ \\
\hline Child, NAcc v. vmPFC & -0.059 & 0.013 & -4.569 & 4188 & $<$ & 0.001 & $* * *$ \\
\hline Adult, $A M Y v . N A c c$ & -0.017 & 0.012 & -1.465 & 3036 & & 1.000 & \\
\hline Adult, $A M Y$ v. vmPFC & -0.016 & 0.012 & -1.341 & 3004 & & 1.000 & \\
\hline Adult, NAcc v. vmPFC & 0.001 & 0.014 & 0.092 & 3357 & & 1.000 & \\
\hline $\begin{array}{l}\text { AMY, Child \& NAcc, Adult v. } \\
\text { AMY, Adult \& NAcc, Child }\end{array}$ & -0.008 & 0.008 & -0.875 & 7558 & & 1.000 & \\
\hline $\begin{array}{l}\text { AMY, Child \& vmPFC, Adult v. } \\
\text { AMY, Adult \& vmPFC, Child }\end{array}$ & -0.041 & 0.009 & -4.766 & 7551 & $<$ & 0.001 & $* * *$ \\
\hline $\begin{array}{l}\text { NAcc, Child \& vmPFC, Adult v. } \\
\text { NAcc, Adults \& vmPFC, Child }\end{array}$ & 0.033 & 0.010 & 3.511 & 7553 & $<$ & 0.001 & $* * *$ \\
\hline
\end{tabular}

Table 1: Bonferroni-Adjusted Age Group \& ROI Contrast Results 


\begin{tabular}{|c|c|c|c|c|c|c|c|}
\hline Contrasts & $\begin{array}{l}\text { Mean } \\
\text { Diff. }\end{array}$ & SE & $\begin{array}{c}\mathbf{T} \\
\text { Statistic }\end{array}$ & df & \multicolumn{3}{|c|}{ Bonferroni P } \\
\hline Positive, Child v. Adult & 0.049 & 0.013 & 3.872 & 3687 & $<$ & 0.001 & $* * *$ \\
\hline Negative, Child v. Adult & 0.109 & 0.013 & 8.693 & 3660 & $<$ & 0.001 & *** \\
\hline Neutral, Child v. Adult & 0.035 & 0.012 & 2.938 & 3710 & & 0.078 & \\
\hline Child, Positive v. Negative & -0.051 & 0.012 & -4.142 & 4196 & $<$ & 0.001 & *** \\
\hline Child, Positive v. Neutral & 0.032 & 0.012 & 2.637 & 4192 & & 0.208 & \\
\hline Child, Negative v. Neutral & 0.083 & 0.012 & 6.882 & 4197 & $<$ & 0.001 & $* * *$ \\
\hline Adult, Positive v. Negative & 0.009 & 0.013 & 0.727 & 3358 & & 1.000 & \\
\hline Adult, Positive v. Neutral & 0.018 & 0.013 & 1.470 & 3347 & & 1.000 & \\
\hline Adult, Negative v. Neutral & 0.009 & 0.013 & 0.720 & 3346 & & 1.000 & \\
\hline $\begin{array}{l}\text { Positive, Child \& Negative, Adult } \\
\text { v. Positive, Adult \& Negative } \\
\text { Child }\end{array}$ & 0.032 & 0.009 & 3.613 & 7558 & $<$ & 0.001 & *** \\
\hline Child, Valenced v. Neutral & 0.057 & 0.010 & 5.504 & 4306 & $<$ & 0.001 & $* * *$ \\
\hline Adult, Valenced v. Neutral & 0.013 & 0.011 & 1.277 & 3542 & & 1.000 & \\
\hline $\begin{array}{c}\text { Valenced, Child \& Neutral, Adult } \\
\text { v. Valenced, Adult \& Neutral, } \\
\text { Child }\end{array}$ & 0.044 & 0.007 & 6.131 & 11306 & $<$ & 0.001 & $* * *$ \\
\hline $\begin{array}{c}\text { Valenced, Child v. Valenced, } \\
\text { Adult }\end{array}$ & 0.079 & 0.009 & 8.863 & 7355 & $<$ & 0.001 & $* * *$ \\
\hline
\end{tabular}


Error: Participant

\begin{tabular}{|c|c|c|c|c|c|c|c|}
\hline Variable & $\begin{array}{l}\text { Sum of } \\
\text { Squares }\end{array}$ & $d f$ & Mean Square & $F$ & $p$ & partial $\omega^{2}$ & Cohen's F \\
\hline Age Group & 11.6 & 1 & 11.63 & 3.56 & 0.066 & 0.008 & 0.088 \\
\hline Residuals & 140.3 & 43 & 3.26 & & & & \\
\hline \multicolumn{8}{|l|}{ Error: Within } \\
\hline Variable & $\begin{array}{l}\text { Sum of } \\
\text { Squares }\end{array}$ & $d f$ & Mean Square & $F$ & $p$ & partial $\omega^{2}$ & Cohen's F \\
\hline ROI & 6.0 & 2 & 2.91 & 21.84 & $<0.001$ & 0.004 & 0.062 \\
\hline Valence & 5.0 & 2 & 2.36 & 17.69 & $<0.001$ & 0.003 & 0.056 \\
\hline ROI * Age Group & 3.0 & 2 & 1.35 & 10.13 & $<0.001$ & 0.002 & 0.042 \\
\hline ROI* Valence & 0.0 & 4 & 0.11 & 0.79 & 0.530 & 0.000 & 0.017 \\
\hline Age Group ${ }^{*}$ Valence & 3.0 & 2 & 1.43 & 10.74 & $<0.001$ & 0.002 & 0.044 \\
\hline Age Group * ROI * Valence & 0.0 & 4 & 0.06 & 0.45 & 0.770 & 0.000 & 0.013 \\
\hline Residuals & 1504.0 & 11279 & 0.13 & & & & \\
\hline
\end{tabular}

Table 3: Mixed Effect ANOVA Results 


\section{A}

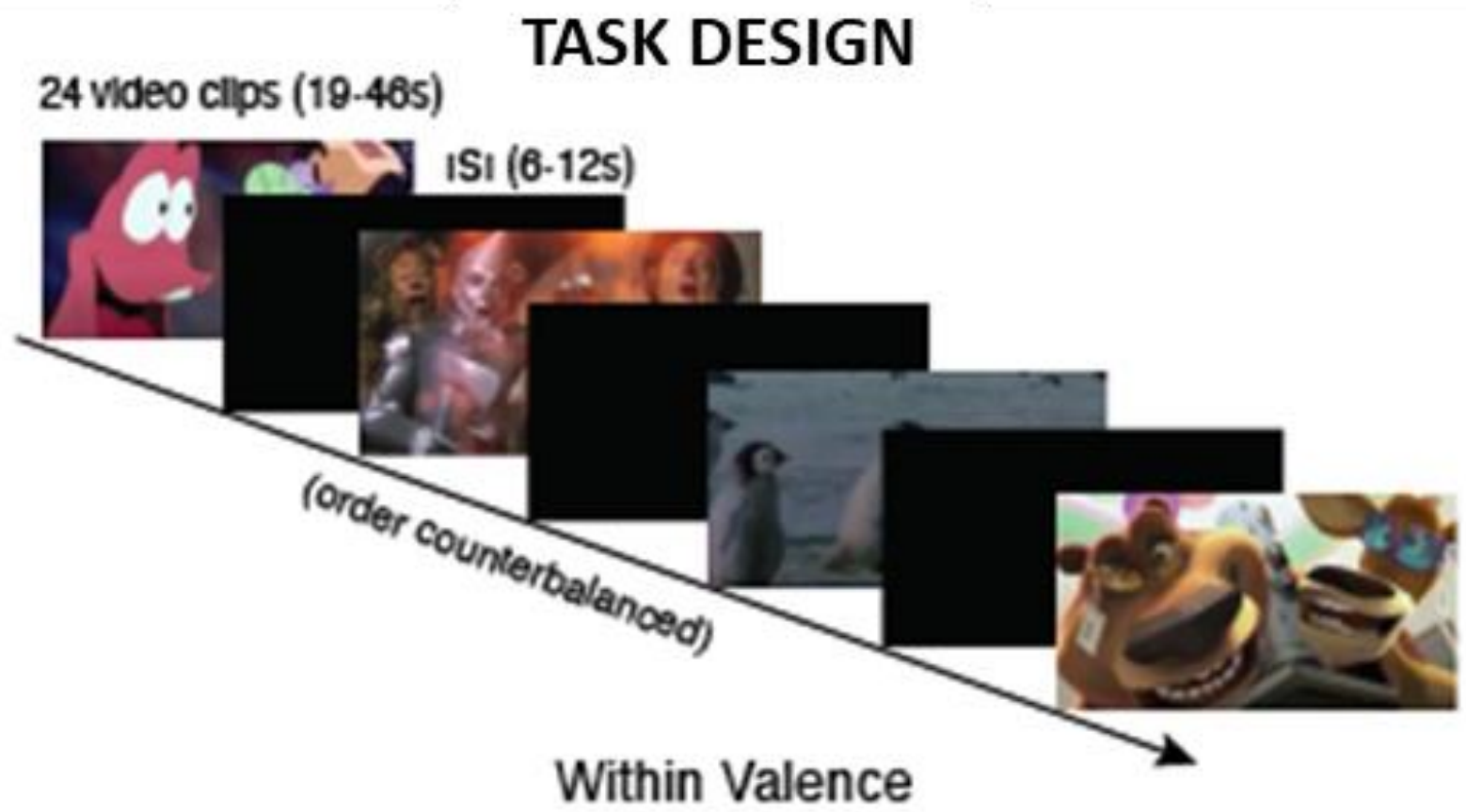

B

Within Valence
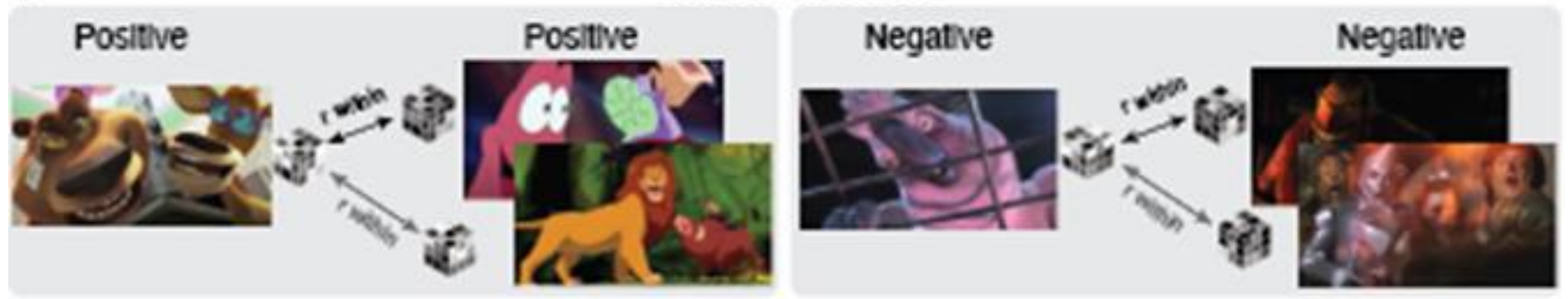

Figure 1A: Participants watched 24 video clips that were randomized into three orders and assigned to participants at random. 1B. We used a representational similarity analysis (RSA) to compute pairwise correlations within positive, negative, or neutral valenced stimuli using Spearman rank-order correlation for non-parametric data. 


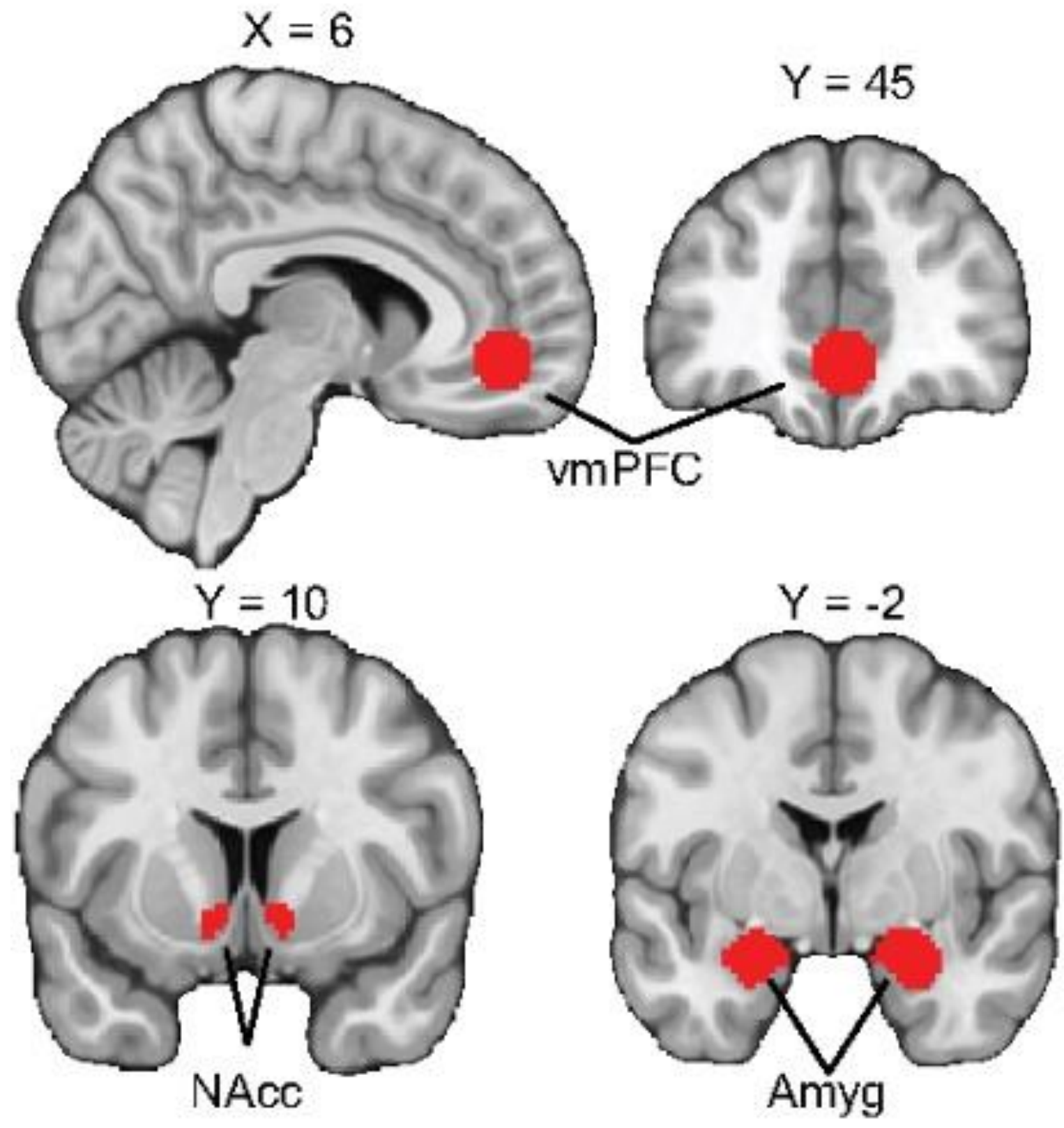

Figure 2: Sagittal and coronal view of vmPFC mask placement. Coronal view of NAcc and amygdala mask placement. 


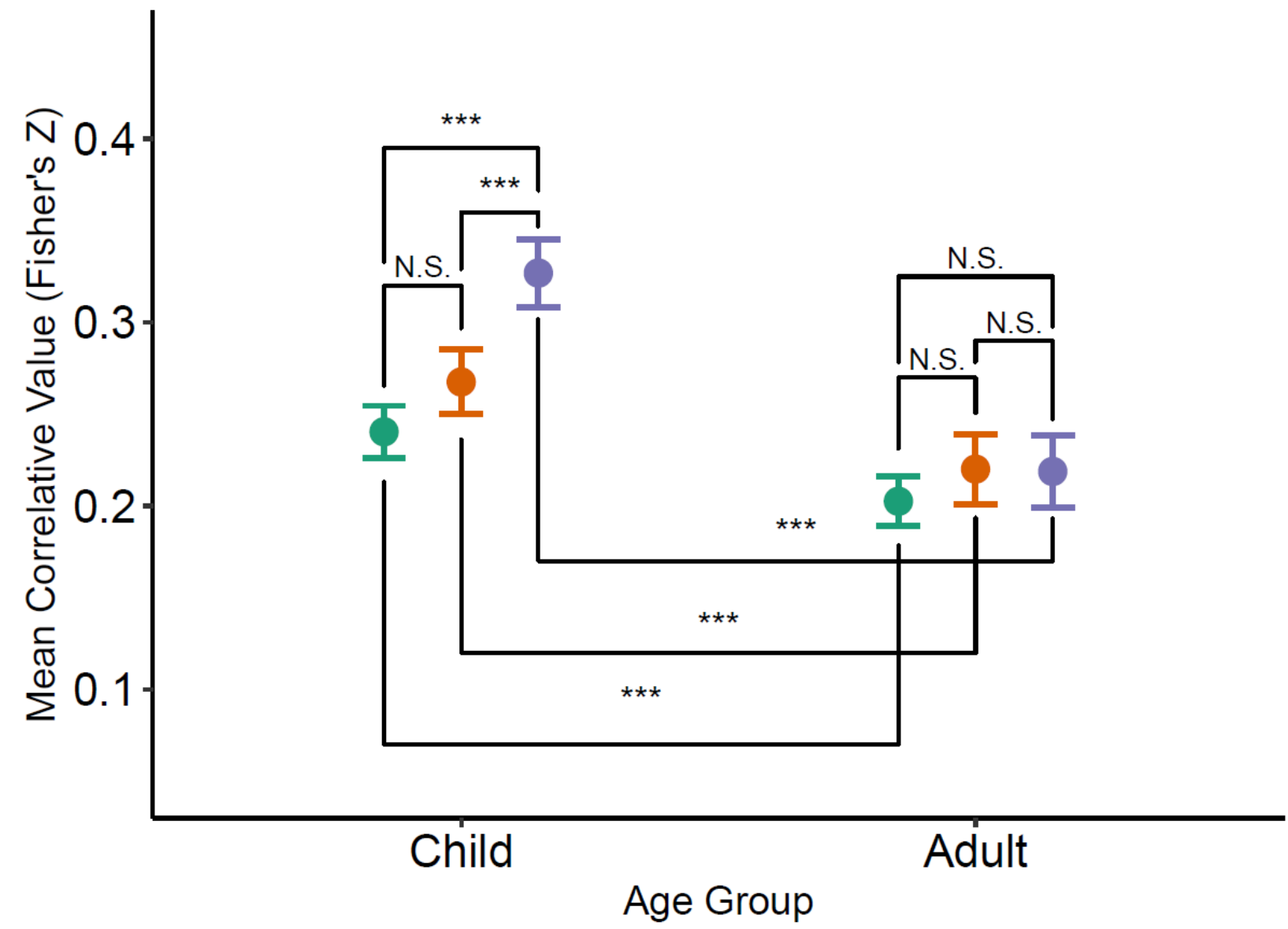

Figure 3: Differences in representational similarity by age group and ROI. No differences exist in representational similarity between Adult AMY, NAcc, and vmPFC. Children's AMY and NAcc differed from vmPFC in representational similarity. Adults and children differed significantly across respective ROIs. NOTE: The full range of our Mean Correlative Value is -1.77 to 1.76 . The range was restricted in this visualization in order to see differences. Error bars represent $95 \%$ confidence intervals. 

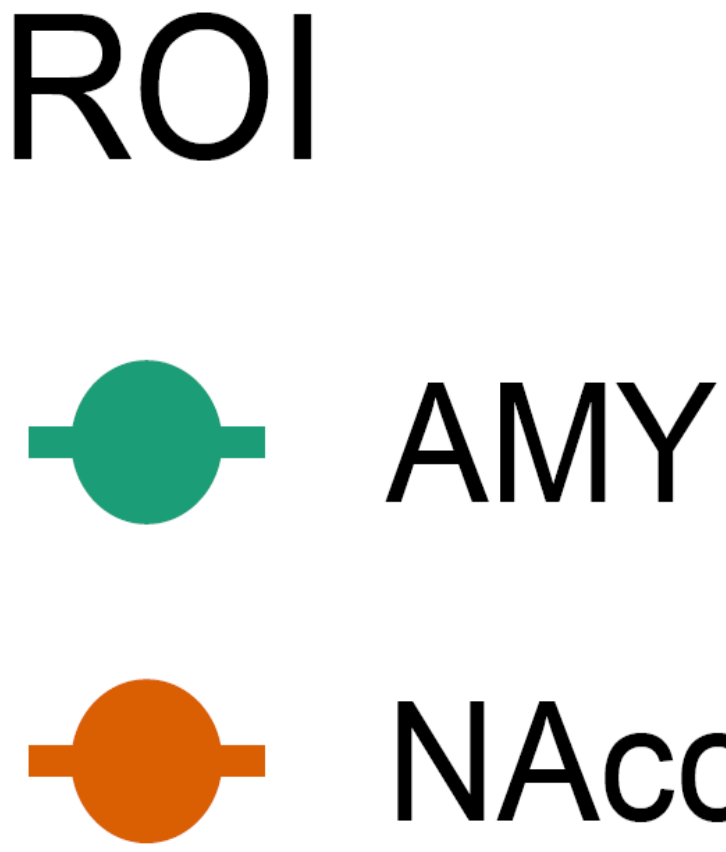

NAcc

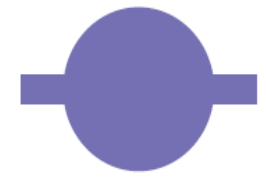

\section{vmPFC}

$$
\begin{aligned}
& p>0.05: \text { N.S. } \\
& p<0.05:^{*} \\
& p<0.01:^{* *} \\
& p<0.001:^{* * *}
\end{aligned}
$$




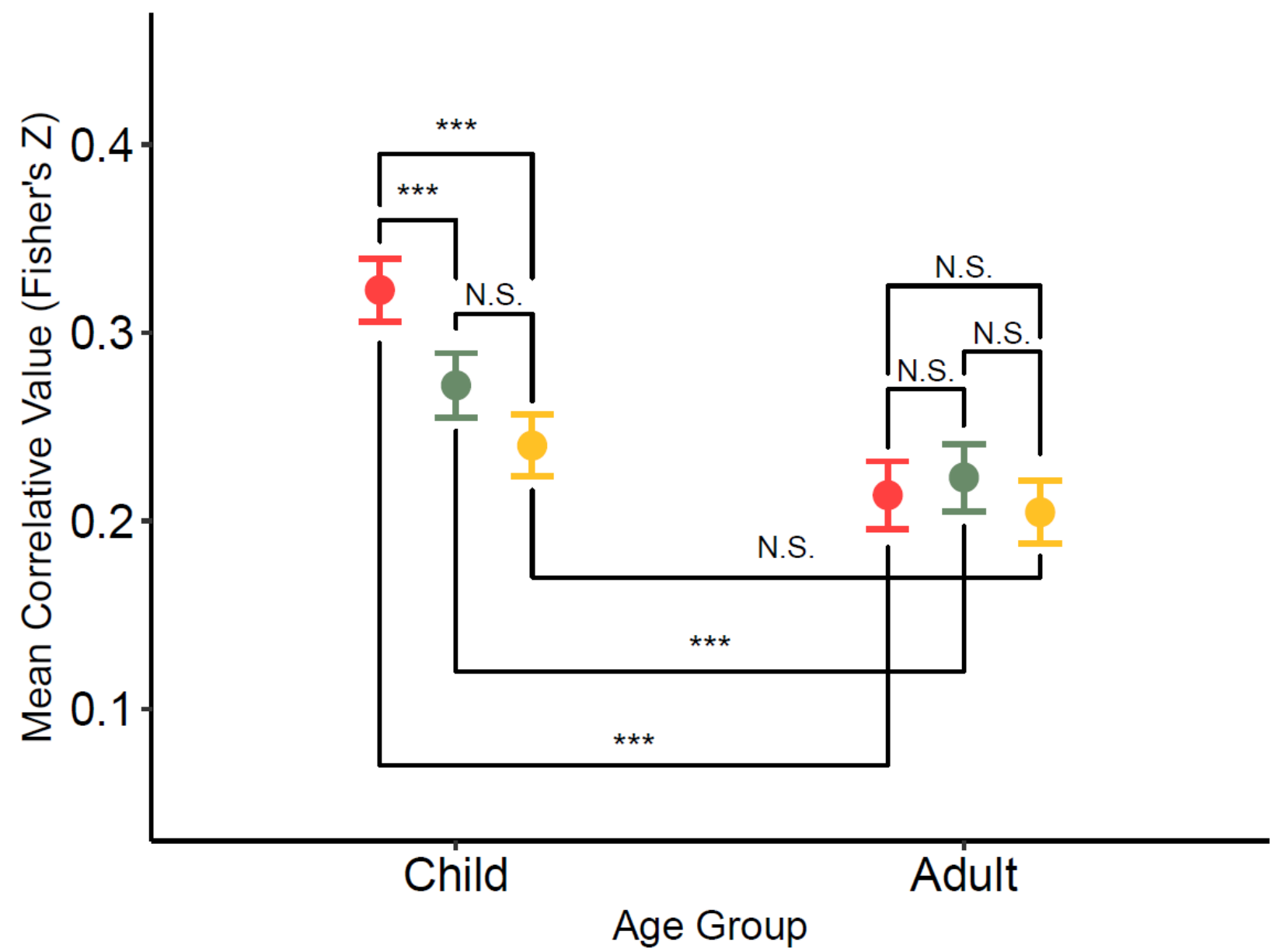

Figure 4: Differences in representational similarity by age and valence. Adults demonstrated no differences in representational similarity by valence. However, children demonstrated greater similarity in negative stimuli relative to positive and neutral stimuli. Age differences were significant between positive and negative, but not neutral stimuli. NOTE: The full range of our Mean Correlative Value is -1.77 to 1.76 . The range was restricted in this visualization in order to see differences. Error bars represent $95 \%$ confidence intervals. 

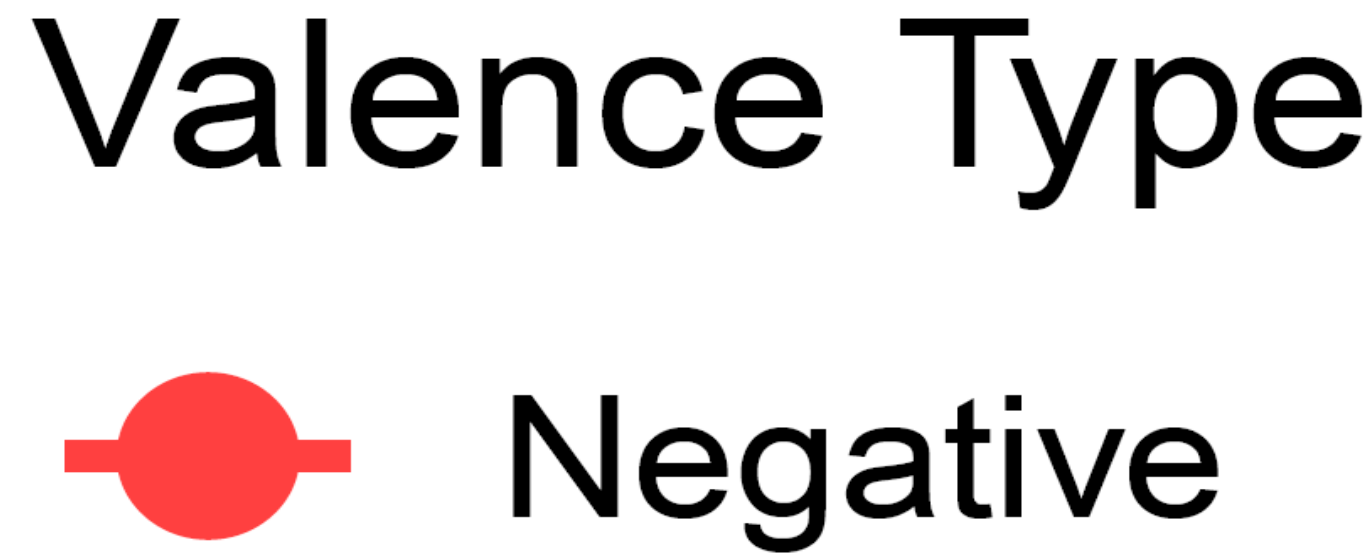

Negative

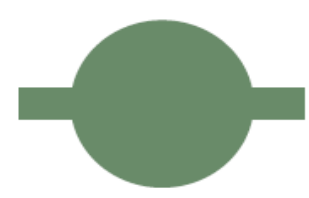

Positive

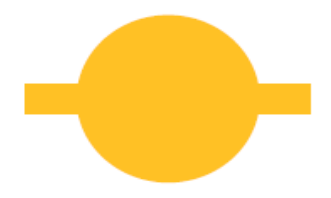

Neutral

$$
\begin{aligned}
& p>0.05: \text { N.S. } \\
& p<0.05:^{*} \\
& p<0.01:^{* *} \\
& p<0.001:^{* * *}
\end{aligned}
$$

